\title{
A spatial assessment of Nipah virus transmission in Thailand pig farms using multi-criteria decision analysis
}

\author{
Weerapong Thanapongtharm ${ }^{1 *}$ D, Mathilde C. Paul ${ }^{2}$, Anuwat Wiratsudakul ${ }^{3}$, Vilaiporn Wongphruksasoong ${ }^{1}$, \\ Wantanee Kalpravidh ${ }^{4}$, Kachen Wongsathapornchai ${ }^{4}$, Sudarat Damrongwatanapokin ${ }^{5}$, Daniel Schar ${ }^{5,6}$ \\ and Marius Gilbert ${ }^{6,7}$
}

\begin{abstract}
Background: Thailand's Central Plain is identified as a contact zone between pigs and flying foxes, representing a potential zoonotic risk. Nipah virus (NiV) has been reported in flying foxes in Thailand, but it has never been found in pigs or humans. An assessment of the suitability of NiV transmission at the spatial and farm level would be useful for disease surveillance and prevention. Multi-criteria decision analysis (MCDA), a knowledge-driven model, was used to map contact zones between local epizootic risk factors as well as to quantify the suitability of NiV transmission at the pixel and farm level.

Results: Spatial risk factors of NiV transmission in pigs were identified by experts as being of three types, including i) natural host factors (bat preferred areas and distance to the nearest bat colony), ii) intermediate host factors (pig population density), and iii) environmental factors (distance to the nearest forest, distance to the nearest orchard, distance to the nearest water body, and human population density). The resulting high suitable areas were concentrated around the bat colonies in three provinces in the East of Thailand, including Chacheongsao, Chonburi, and Nakhonnayok. The suitability of NiV transmission in pig farms in the study area was quantified as ranging from very low to medium suitability.

Conclusions: We believe that risk-based surveillance in the identified priority areas may increase the chances of finding out NiV and other bat-borne pathogens and thereby optimize the allocation of financial resources for disease surveillance. In the long run, improvements of biosecurity in those priority areas may also contribute to preventing the spread of potential emergence of NiV and other bat-borne pathogens.
\end{abstract}

Keywords: Nipah virus, MCDA, Thailand, Flying foxes, Risk-based surveillance

\section{Background}

Bat species have been identified as the reservoir of many pathogens infecting humans and animals. Pteropid bats (flying foxes) were found to be the natural host of the Henipavirus family that includes the Hendra virus $(\mathrm{HeV})$ and the Nipah virus (NiV). HeV causes acute and highly fatal infection in humans and horses, was first described in Brisbane, Australia in 1994 [1]. Similar to $\mathrm{HeV}, \mathrm{NiV}$ causes a range of clinical outcomes but primarily respiratory distress and encephalitis [2-4], and was first

\footnotetext{
* Correspondence: weeraden@yahoo.com

'Department of Livestock Development (DLD), Bangkok, Thailand

Full list of author information is available at the end of the article
}

isolated from human patients and pigs in Malaysia in 1998 [5].

In tropical Asia, $\mathrm{NiV}$ is considered to be the main human and animal health concern among the viruses carried by bats. Even though flying foxes are found throughout tropical and sub-tropical Asia and Australia and on islands of the Indian Ocean and the western $\mathrm{Pa}$ cific [6], NiV was mainly found in flying foxes with subclinical infections in tropical Asia (Malaysia, Cambodia, Thailand, Bangladesh, and India) [3, 7-10]. During the first NiV occurrence in Malaysia in 1998, pigs were found to be an amplifier. It is believed that $\mathrm{NiV}$ was passed from flying foxes to pigs and subsequently spilled

(c) The Author(s). 2019 Open Access This article is distributed under the terms of the Creative Commons Attribution 4.0 International License (http://creativecommons.org/licenses/by/4.0/), which permits unrestricted use, distribution, and 
over from pigs to other animals and humans [5, 11, 12]. Studies in Bangladesh also suggested that NiV may have passed directly from bats to humans without an amplification host $[9,13]$, and human-to-human transmission was observed in several outbreaks in Bangladesh and India [9-11].

In Thailand, $\mathrm{NiV}$ has been sampled from flying foxes since 2002 but no evidence of the virus in domestic animals has been found so far. Blood, saliva and urine samples of flying foxes ( $P$. hypomelanus, $P$. vampyrus, and $P$. lylei) were collected during 2002-2004. All samples were tested in the Molecular Biology Laboratory for Neurological Diseases, Chulalongkorn University Hospital, with positive results to $\mathrm{NiV}$ presence and $\mathrm{NiV}$ antibody [8]. A longitudinal study was subsequently conducted on flying foxes (only P. lylei) between 2005 to 2007, which showed that two NiV strains previously identified circulating in Malaysia and Bangladesh were found in the bat's urine [14]. The Department of Livestock Development (DLD) has been conducting surveillance of NiV infection in domestic pigs with serological and virological detection, and no $\mathrm{NiV}$ positive sample was ever found so far [15-17].

In the last few decades, Thailand's pig production gradually increased with a continuing intensification of the sector [18]. The concentration was particularly marked in Thailand's Central Plain because of its easy access to the major market of the Bangkok Metropolitan region [18]. Coincidentally, flying fox colonies are found mainly in the same areas [19-21], influenced by the availability of numerous water bodies (for drinking and releasing heat by dipping) and agricultural activities (for foraging) [21]. The region is also characterized by a fairly high human population density. Therefore, the regions surrounding the Bangkok metropolitan region appear as potential high-risk contact zones for NiV transmission among bats, pig and human population [18].

In a previous study, we used Potential surface analysis (PSA) as a first attempt to map suitable areas of $\mathrm{NiV}$ transmission to pigs in Thailand's Central Plain [21]. The areas identified as higher suitability of NiV transmission were located around the Bangkok metropolitan area, covering $5417 \mathrm{~km}^{2}$ of 607 sub-districts, 125 districts, and 23 provinces [21]. However, the approach was limited by the somewhat arbitrary choices of weights of risk factors that were made along the process [21]. Furthermore, the approach did not allow incorporating risk factors at the farm level. The identification of relevant risk factors, their weights and the way they increase the risk spatially, or at the farm level, may be defined in a more explicit and thorough way in using a multi-criteria decision analysis approach $[21,22]$. Therefore, the objectives of this study was to develop two complementary MCDA models, one aiming to map the suitability of NiV presence at the pixel level, and a second one aiming to quantify the suitability of $\mathrm{NiV}$ transmission at the farm level.

\section{Results}

\section{Spatial model}

The results of the decision making process are shown in Table 1. Seven spatial risk factors were identified by the experts: i) the bat preferred area, ii) the distance to the nearest bat colony, iii) the distance to the nearest forest, iv) the distance to the nearest orchard, v) the distance to the nearest water body, vi) the human population density, and vii) the pig population density. The results showed that, according to the experts, the distance to the nearest bat colony had the highest weight, followed by the pig population density, the bat preferred area, the distance to the nearest orchard, the distance to the nearest forest, and the distance to the nearest water body, respectively.

The resulting high-suitability areas were clustered nearby the bat colonies, but varying levels of risk could be observed depending on their surrounding (Fig. 1). The high-suitable areas, defined as those with a scale > 0.6 were extracted and aggregated the district level that would make them more conveniently usable by local veterinary officers. Twenty-seven provinces contained at least one pixel ranked as high-suitability, but this number was reduced to 18 provinces (101 districts and 496 sub-districts) by removing high-suitability areas covering less than $1 \mathrm{~km}^{2}$. The three provinces in the East of Thailand, including Chacheongsao, Chonburi, and Nakhonnayok, were found to be the one with the largest areas of high suitability of NiV transmission.

For the OAT sensitivity analysis, the simulated suitability maps for NiV transmission in pigs in the Central Plain of Thailand were generated with the weight of each factor changed from -25 to $25 \%$ with a step size of $1 \%$. The MACRs were used to display the sensitivity of each factor, which a high gradient indicates a greater change in values of the output maps (high sensitivity). As a result (Fig. 2), the outputs were most sensitive to human population density, followed by the distance to the nearest bat colony, the pig population density, the bat preferred area, the distance to the nearest forest, the distance to the nearest orchard, and the distance to the nearest water body.

The uncertainty analysis showed a fairly robust result and a spatial heterogeneity. The uncertainty surface remained stable with the maximum standard-deviation value (STD) being less than 0.1 (Fig. 3) even through risk factors were varied. This implies that the predicted suitability areas for NiV transmission in pigs in the Central Plain of Thailand according to the suitability index are fairly robust. The result also showed a spatial heterogeneity in uncertainty, with 
Table 1 Spatial risk factors, standardized methods, and relative importance of each factor

\begin{tabular}{|c|c|c|c|c|c|c|}
\hline \multirow[t]{2}{*}{ Factors } & \multirow[t]{2}{*}{ Fuzzy membership functions } & \multicolumn{4}{|c|}{ Inflection points } & \multirow[t]{2}{*}{ Weights } \\
\hline & & $a$ & $\mathrm{~b}$ & c & $d$ & \\
\hline Bat preferred area & Sigmoidal, monotonically increasing & 0 & 0.5 & 0.5 & 0.5 & 0.18611 \\
\hline Distance to the nearest bat colony & Sigmoidal, monotonically decreasing & $5 \mathrm{~km}$ & $5 \mathrm{~km}$. & $5 \mathrm{~km}$. & $30 \mathrm{~km}$. & 0.28016 \\
\hline Distance to the nearest forest & Linear, monotonically decreasing & $100 \mathrm{~m}$ & $100 \mathrm{~m}$ & $100 \mathrm{~m}$ & $23 \mathrm{~km}$. & 0.06887 \\
\hline Distance to the nearest orchard & Linear, monotonically decreasing & 0 & 0 & 0 & $500 \mathrm{~m}$ & 0.11719 \\
\hline Distance to the nearest water body & Linear, monotonically decreasing & 0 & 0 & 0 & $1 \mathrm{~km}$ & 0.03663 \\
\hline Human population density & Sigmoidal, monotonically decreasing & 100 per $\mathrm{km}^{2}$ & 800 per $\mathrm{km}^{2}$ & 800 per $\mathrm{km}^{2}$ & 800 per $\mathrm{km}^{2}$ & 0.06979 \\
\hline Pig population density & Linear, monotonically increasing & 0 per km2 & 1,000 per km2 & 1,000 per km2 & 1,000 per km2 & 0.24126 \\
\hline
\end{tabular}

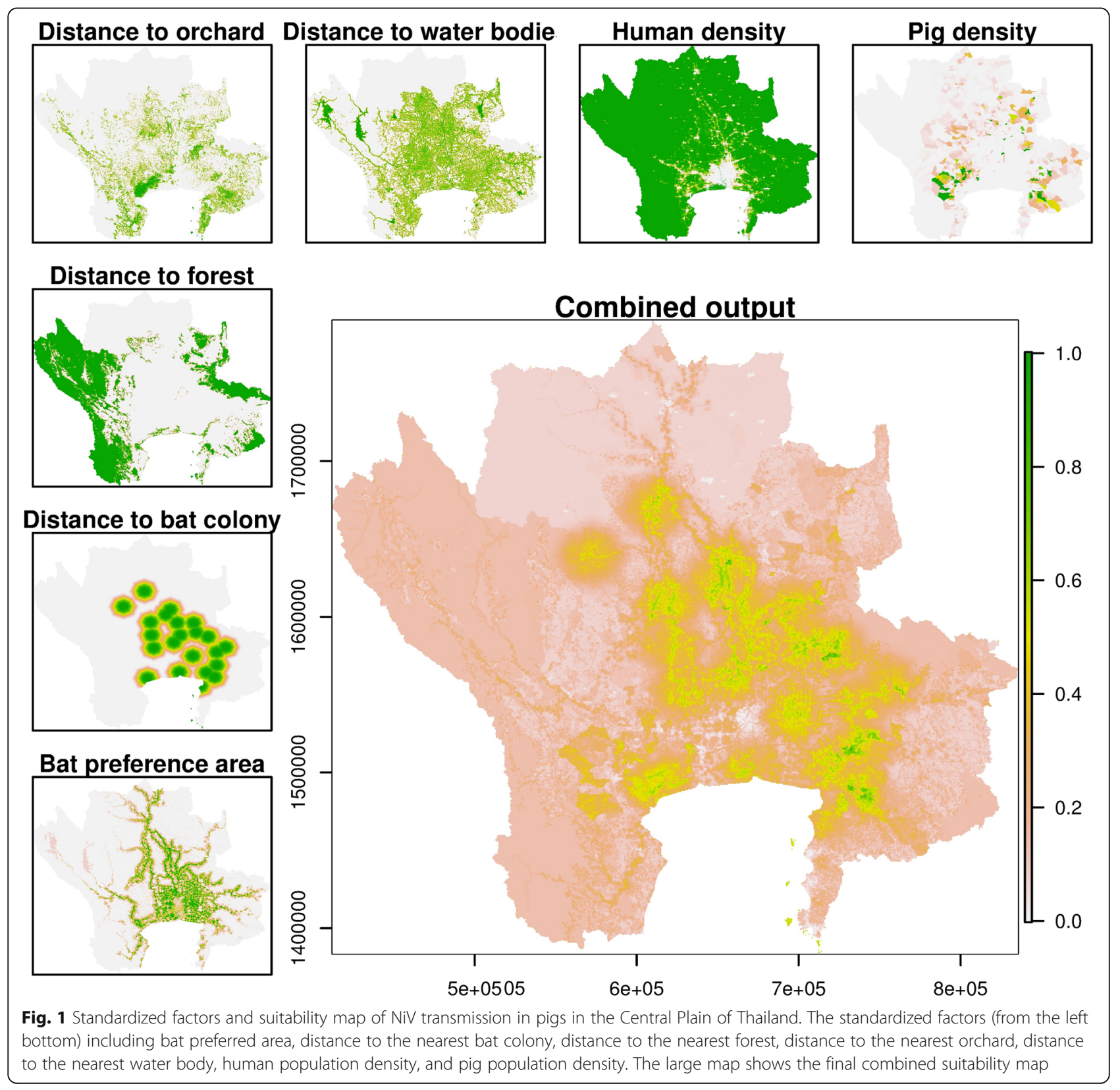




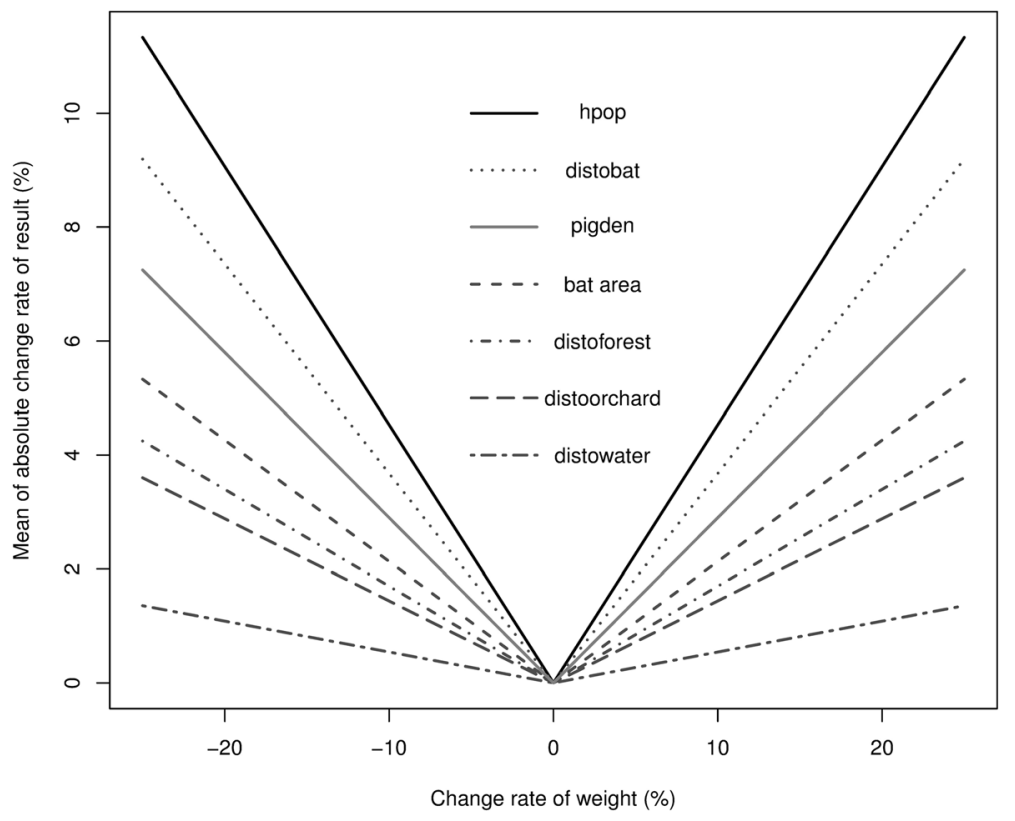

Fig. 2 Mean absolute values of the change rate (MACRs) for the suitability maps under simulations. (hpop: human population density, distobat: distance to the nearest bat colony, pigden: pig population density, batarea: bat preferred area, distoforest: distance to the nearest forest, distoorchard: distance to the nearest orchard, and distowater: distance to the nearest water body)

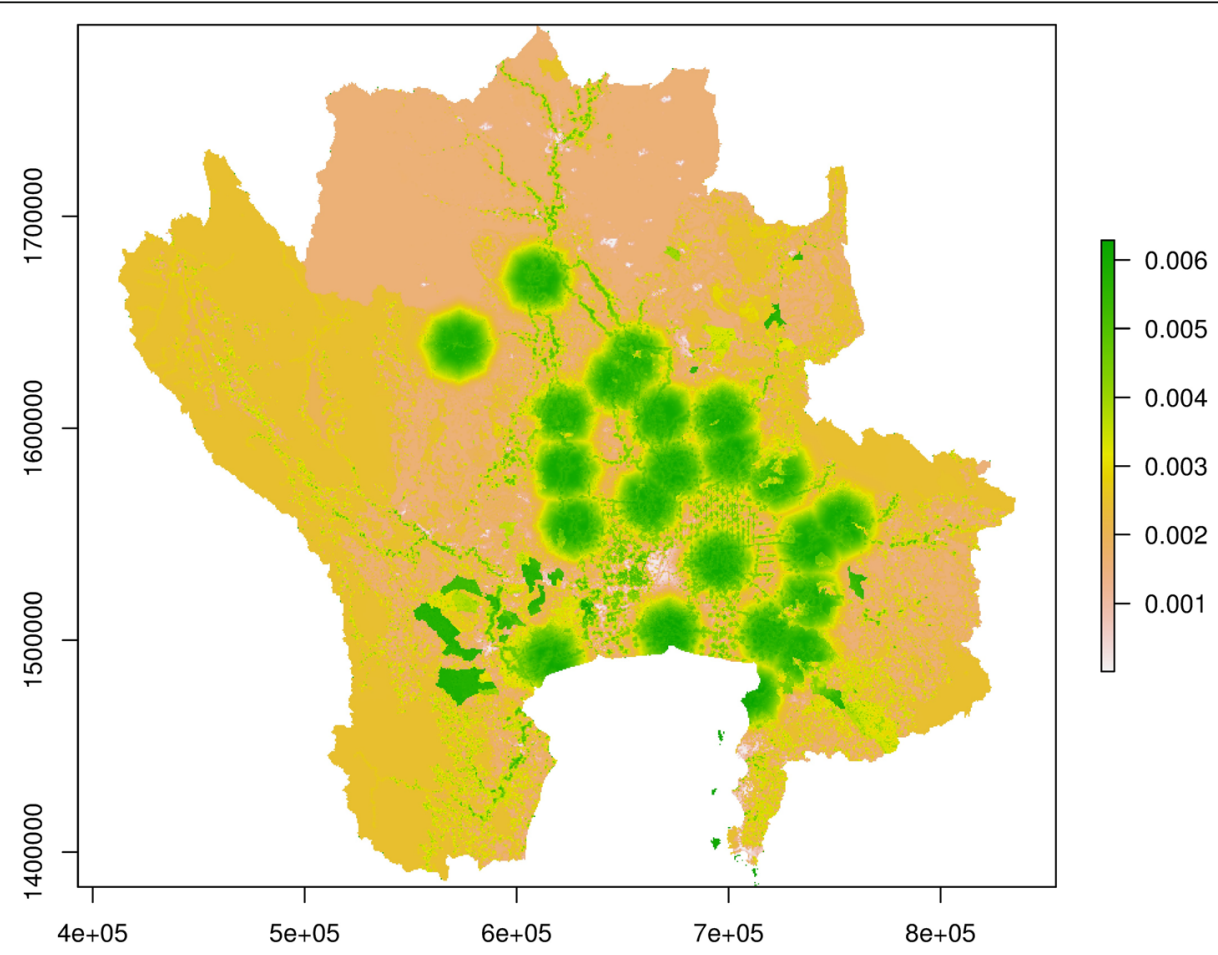

Fig. 3 Uncertainty map. The map shows standard deviation of the suitability maps for NiV transmission in pigs in the Central Plain of Thailand 
higher uncertainty in high suitability areas of NiV transmission in pigs.

\section{Farm model}

The results of the decision making process are shown in Table 2, which details the risk factors, their scale and weight. The experts defined twelve risk factors that would be important at the farm level. The three most important identified factors were the type of pig house, and the presence and frequency of flying foxes found in the farm area. The final score of each farm was from the WLC method, categorized in 5 suitability levels $(<1.5=$ very low, $>1.5-2.5=$ low, $>2.5-3.5=$ medium, $>3.5-4.5$ $=$ high, and $>4.5=$ very high). As shown in Fig. 4 , there were 7 farms with very low suitability, 46 farms with low suitability, 30 farms with medium suitability, and 6 farms with high suitability. The mean score of the 89 farms was 2.374 with a standard deviation of 0.721 . The breakdown of suitability at the farm level and by farm size is presented in Table 3. One can note that the high suitable farms were small-scale ( 3 farms, $<500$ pigs/farm) and medium-scale farms (3 farms, 1000-5000 pigs/farm), and that the majority of farms were ranked in the low (46) and medium (31) suitability.

\section{Discussion}

GIS-based MCDA was used in this study to evaluate the suitability for NiV transmission in pigs in Thailand in the absence of actual data in $\mathrm{NiV}$ occurrence in pigs. Data-driven models are far more frequently used to infer risk and to quantify the association between an event of interest (such as disease occurrences) and explanatory variables by using statistics [23]. For example, autoregressive logistic regression models and boosted regreesion tree models have been used to model the distribution of Highly Pathogenic Avian Influenza (HPAI) H5N1 [24-27] and Porcine Reproductive and Respiratory Syndrome (PRRS) in Thailand [28]. However, as NiV has never been reported in pigs or domestic animals in Thailand, data-driven models could not be applied. With the present situation, NiV exists in the country [8] and the neighboring countries $[3,7,9,10]$ carried by the flying foxes; therefore, the prevention of $\mathrm{NiV}$ transmitted to pigs should be immediately implemented by targeting the specific areas and farms with high chances of NiV occurrence. Knowledge-driven models such as Potential surface analysis (PSA) or MCDA provide an interesting alternative to model the suitability of NiV distribution in space, or at the farm level as a way to prioritize surveillance and improve prevention [8]. Knowledge-based models have been found to provide fairly good accuracy metrics in previous studies [29], but these somewhat benefited from several years of experience and published papers where data-driven approaches had been used to identify important risk factors. So, in situations where very little is known about a disease and its main risk factors, their outputs help converting the current state of knowledge into a visualisation where all factors are combined together, but the quality of the predictions may be compromised by the misidentification of some unknowns factors.

In this regard, the current lack of epidemiological knowledge on $\mathrm{NiV}$ in pigs is a limitation of this study.

Table 2 Risk factors in farm level, standardized methods, and relative importance of each factor

\begin{tabular}{|c|c|c|c|c|c|c|}
\hline Factors & Very low (1) & Low (2) & Medium (3) & High (4) & Very high (5) & Weight \\
\hline Certified standard farm & Yes & & $\begin{array}{l}\text { Submitted but not } \\
\text { certified }\end{array}$ & & Not certified & 0.05652 \\
\hline Type of pig house & Close (evaporation) & Close (wind tunnel) & Open (net) & & Open (no net) & 0.22995 \\
\hline $\begin{array}{l}\text { Flying fox bat }(s) \text { found in } \\
\text { farm area }\end{array}$ & Never & & A bat flying through & A bat eating in farm & $\begin{array}{l}\text { A bat roosting } \\
\text { in farm }\end{array}$ & 0.13653 \\
\hline $\begin{array}{l}\text { Frequency of flying fox bat } \\
\text { (s) found in farm area }\end{array}$ & Never & $\begin{array}{l}\text { Seldom }(<12 \text { times } \\
\text { per year) }\end{array}$ & $\begin{array}{l}\text { Occasionally (at least } \\
\text { a time per month) }\end{array}$ & $\begin{array}{l}\text { Often }(>2 \text { times } \\
\text { per week) }\end{array}$ & $\begin{array}{l}\text { Always (almost } \\
\text { every day) }\end{array}$ & 0.13653 \\
\hline Presence of fruit trees in farm & No & & $<20$ trees & & $>20$ trees & 0.06654 \\
\hline $\begin{array}{l}\text { Number of fruit trees less than } \\
15 \mathrm{~m} \text {. away from the pig house }\end{array}$ & No & & & $<5$ trees & $>5$ trees & 0.10251 \\
\hline Presence of high trees in farm & No & $<20$ trees & & $>20$ trees & & 0.03272 \\
\hline $\begin{array}{l}\text { Number of high trees being less } \\
\text { than } 15 \mathrm{~m} \text {. away from pig house }\end{array}$ & No & & $<5$ trees & $>5$ trees & & 0.06367 \\
\hline Type of other animals in farm & No & Others & Cow/horse/goat & Dog/cat & Rodent & 0.02538 \\
\hline Presence of fence surrounding farm & Yes & & & No & & 0.02643 \\
\hline $\begin{array}{l}\text { Quarantine of at least } 14 \text { days before } \\
\text { introduction of new pig }\end{array}$ & Yes & & & No & & 0.02643 \\
\hline $\begin{array}{l}\text { Spatial suitability of NiV transmission } \\
\text { where this pig farm is located }\end{array}$ & Very low & Low & Medium & High & Very high & 0.09678 \\
\hline
\end{tabular}




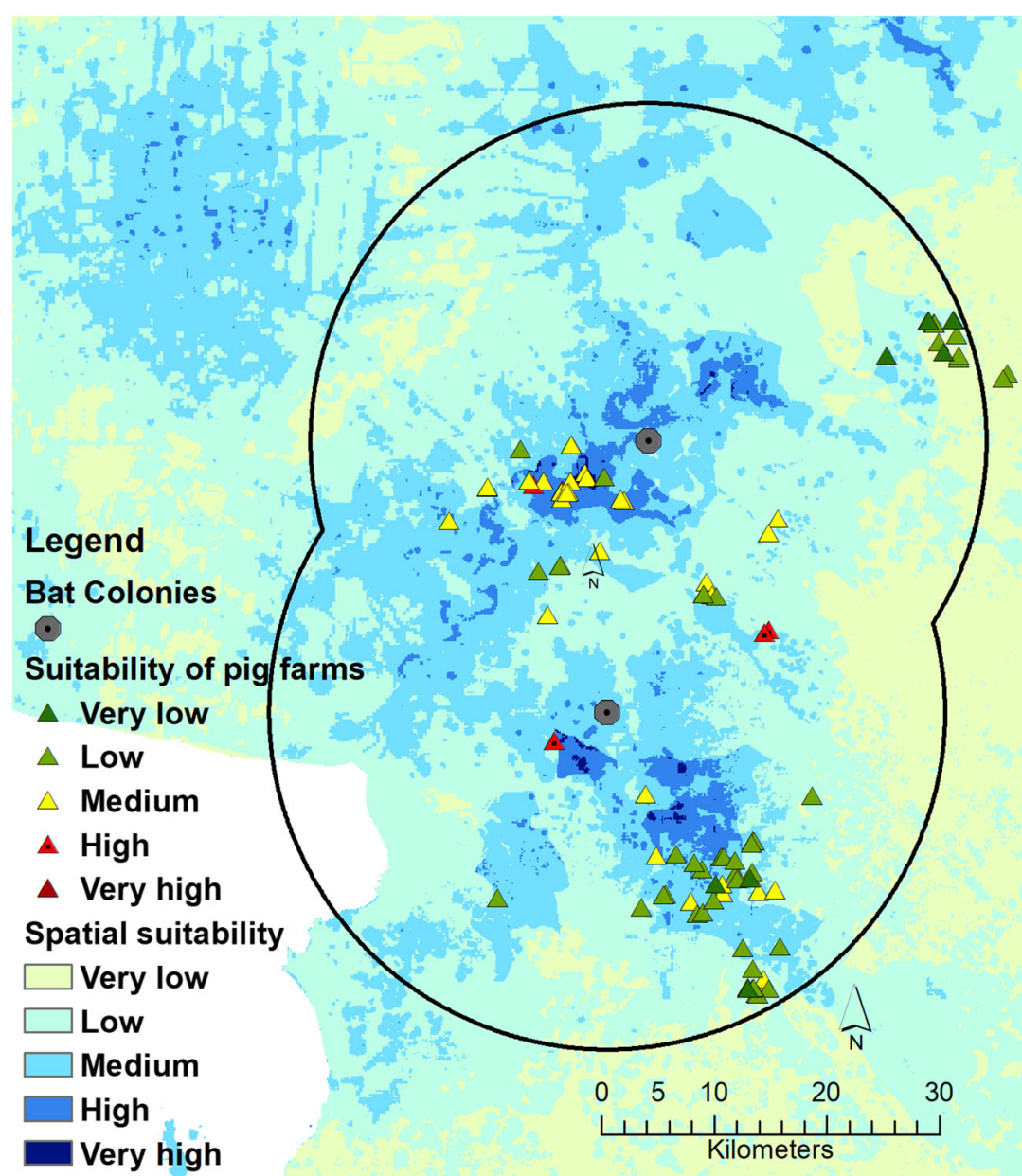

Fig. 4 The suitability of NiV transmission in spatial and farm level in study area. Map shows the suitability levels of 89 pig farms (from farm model) within a 30-km radius surrounding two bat colonies in the East of Thailand overlayed on the spatial suitability of NiV transmission (from spatial model)

The two possible sources of a priori knowledge include literature review and experts' opinion [30,31] to identify spatial risk factors. One should note that those two sources are rarely independent, because the expert opinion can be influenced by their knowledge of the published litterature, and the litterature is itself produced by

Table 3 Suitability levels of pig farms classified by farm size

\begin{tabular}{|c|c|c|c|c|c|c|}
\hline \multirow{2}{*}{$\begin{array}{l}\text { Farm size } \\
\text { (Pig/farm) }\end{array}$} & \multicolumn{6}{|c|}{ Suitability levels } \\
\hline & $\begin{array}{l}\text { Very low } \\
(<1.5)\end{array}$ & $\begin{array}{l}\text { Low } \\
(1.5-2.5)\end{array}$ & $\begin{array}{l}\text { Medium } \\
(2.5-3.5)\end{array}$ & $\begin{array}{l}\text { High } \\
(3.5-4.5)\end{array}$ & $\begin{array}{l}\text { Very high } \\
(>4.5)\end{array}$ & Total \\
\hline$<100$ & 0 & 1 & 1 & 2 & 0 & 4 \\
\hline $100-500$ & 3 & 8 & 6 & 1 & 0 & 18 \\
\hline $500-1000$ & 1 & 21 & 10 & 0 & 0 & 32 \\
\hline $1000-5000$ & 3 & 15 & 11 & 3 & 0 & 32 \\
\hline$>5000$ & 0 & 1 & 2 & 0 & 0 & 3 \\
\hline Total & 7 & 46 & 30 & 6 & 0 & 89 \\
\hline
\end{tabular}

experts. The only litterature on $\mathrm{NiV}$ in Thailand concerned bats $[8,32,33]$, so there was little experience of the experts with what may be applicable to the country, and the national expert views would have been mostly informed by knowledge gained from epidemiological reports from other countries where $\mathrm{NiV}$ was found. The subjectivity associated with experts' choices in the consideration of risk factors, membership functions and weights also has indeed been often identified as an important limitation of the MCDA approaches [30, 31]. Furthermore, map validation could not be applied in this study in the absence of presence data [30].

The geographical conditions found in the Central Plain of Thailand are favourable not only to livestock development but also provide good habitats for flying foxes' colonies. The Central Plain is recognized as the major feed production area in Thailand, with an abundant supply of rice bran and broken rice, low transport cost and short shipment time to the major consuming centre (Bangkok) 
as well as ports for export [18]. It is a large and fertile area able to supply a dense human population [34], with flat landscape and a well-developed irrigation system for wet-rice agriculture. Metropolitan Bangkok, the focal point of trade, transport, and industrial activity, is situated on the southern edge of the region at the head of the Gulf of Thailand [34]. The livestock industry has therefore developed particularly in these areas, supplying both national and international markets. Large-scale pig farms found in the suburban areas surrounding the main cities, particularly around the Bangkok Metropolitan region [18] are mainly commercial (breeding and fattening) pig farms. A similar spatial pattern was previously reported for poultry [35], where most of the intensively production units are concentrated around Bangkok. Unfortunately, flying fox colonies are also found mainly on Thailand's Central Plain, particularly in locations surrounded by bodies of water (for drinking and cooling down), vegetation (for foraging), and safe havens such as Buddhist temples (for survival from human hunting) [21]. So, intensification of pig production in this particular region over time may have created favorable conditions for transmission of NiV to pigs.

Spatial risk factors of $\mathrm{NiV}$ transmission in pigs identified by experts in this study were associated with three components of the landscapes including i) natural host (bat preferred area and distance to the nearest bat colony), ii) intermediate host (pig population density), and iii) environment (distance to the nearest forest, distance to the nearest orchard, distance to the nearest water body, and human population density). The bat preferred area (potentially suitable sites) was mapped according to the assumption that bat colonies may move from one site to another [21]. The distribution of flying fox colonies is dynamic and changes have been observed over time [19-21], caused by different factors such as hunting, damage of roosting trees, invasion by other species, or simply to expand the sizes of the colony [21]. A short distance to bat colonies was identified as a particularly important risk factor in this study. Foraging individuals commuting between day roosts and foraging areas each night were studied using high-resolution global positioning system (GPS) loggers, and these studies showed that the maximum linear distances covered during a night varied greatly between individuals, ranging between 2.2 and $23.6 \mathrm{~km}$ [36]. The study also reported that tracked bats mostly foraged in farmland, plantations, small mangrove remnants, and gardens [36]. This justified the distance to the nearest forest and the distance to the nearest orchard as factors to be considered in this analysis. The distance to the nearest water body was considered based on the behavior of bats that need water for drinking $[37,38]$ and that have been observed cooling down in large water bodies on hot days $[39,40]$. The human population density was considered as a spatial factor because the flying foxes are likely to forage away from high human density area caused by hunting [21]. A pig population density was also included in the study. A detailed investigation carried out in Malaysia indicated that NiV epidemics could have been caused by intensifying agriculture (pig and mango production) in the country $[5,12,41]$.

Improvement of biosecurity at the farm level can strongly reduce the risk of animal-to-pig transmission. The risk factors at the farm level identified by experts were related to three possible sources of $\mathrm{NiV}$ including flying foxes, infected pigs, and infected other animals such as dogs, cats, goats, sheep and horses. This was based on investigation of the index case (first occurrence case) in Malaysia reporting that pigs were first infected by $\mathrm{NiV}$ shed by flying foxes through their urine or partial-eaten fruits [12]. Further investigation showed the virus to subsequently spill over from pigs to other animals and humans via respiratory droplets or close contact $[5,11]$. Therefore, such infected pigs (from other farms) and infected other animals (both inside and outside farm) may possibly transmit NiV to pigs as well. So, avoiding interface between pigs and the possible sources by improving biosecurity at the farm level could prevent bat-to-pig, pig-to-pig, and animal-to-pig transmission. Several example of measures could be considered such as i) the use of nets to cover pig houses to prevent the contact between pigs and flying foxes, ii) the cutting down of fruit trees that are nearby the pig houses to reduce farm attractivity, iii) the quarantine and observation of new pigs before they enter the pig houses, or iv) the use of fence to prevent other animals from entering the pig farm.

Although suitability evaluation of pig farms in the study area mostly showed farms classified as big at very low to medium suitability, some pig farms had higher suitability scores. The fact that the majority of pig farms in the study area $(93.3 \%)$ had very low to medium suitability of $\mathrm{NiV}$ transmission is in fact not so surprising. The area corresponds to the foot and mouth disease (FMD) free-zone of Thailand [16], where strong surveillance of FMD gives access to international markets. FMD is indeed an important trade barrier due to its high capacity to be transmitted to a wide range of hosts including cattle, pigs, goat, sheep, and other ruminants with a high economic impact [42]. Pig production intensified in Thailand, with a shift from extensive production systems (raise small amount of pigs for household consumption and additional income) towards more intensive production systems (commercial purpose) [18]. These changes were particularly marked in Eastern Thailand where the predominance of intensive pig production systems promoted the establishment of the FMD-free zone to gain access to international markets. 
However, in order to gain the FMD-free zone status, most pig farms in this part of Thailand have been improving their biosecurity and these provinces now contain a lower proportion of small intensive farms than many other Thailand provinces. Our results showed 6 pig farms (6.7\%) presenting a high suitability, with 3 small-scale farms $(<500$ pigs per farm) and 3 medium-scale farms (between 1000 and 5000 pigs per farm). These may need further investigation and possible increased surveillance and biosecurity measures.

The farm-level evaluation of NiV suitability was only performed in limited areas, and as our results demonstrate, these could be expanded to other parts of Thailand's Central Plain in order to have a more comprehensive overview of the farms at risk. In this regard, the results of the spatial model may be particularly useful, as they may guide the deployment of farm-level surveys in other areas. Eighteen provinces with 101 districts and 496 sub-districts were identified as high-suitability areas of $\mathrm{NiV}$ infection by the spatial model. Farm-level suitable quantification using questionnaire developed on mobile (phone or tablet) applications could be implemented by firstly focusing on all pig farms located in the high suitable districts and then expanding to medium and low suitable districts. In addition, since several of the risk factors are somewhat generic (e.g. presence of fence, quarantine of entering animals), this may allow having a broader overview of risk factors at the farm level that could be relevant to other diseases. In this regard, the addition of other risk factors relevant to other diseases may be added to the questionnaire. This would also present several opportunities to inform the farmers on the way to improve biosecurity and reduce the risk of $\mathrm{NiV}$ infection, but also of other diseases such as FMD or PRRS. Biosecurity is the implementation of measures that reduces the risk of the introduction and spread of disease agents [43], or in other words, the "keep microbes away from pigs" and/or "keep pigs away from microbes" [43]. One should note that biosecurity does not necessarily reflect the same practical measures in high-income countries, where it mostly correspond to large investments in infrastructures and equipment, than in low or middle income countries, where biosecurity improvements in the smallholder sector can already be achieved through very simple and low-cost precautionary measures [44].

\section{Conclusions}

The spatial and farm suitability models developed here could be immediately applied to implement risk-based surveillance and to improve biosecurity in the long run. The implementation of risk-based surveillance with prioritized areas and farms may increase the chances of detecting $\mathrm{NiV}$ and other bat-borne pathogens in pig farms, and also reduce the financial burden of animal disease surveillance [45]. So far, the targeted surveillance implemented by the Department of Livestock Development (DLD) has been focusing on areas according to their pig density [16], but this may have missed the critical influence of other factors. The MCDA approach allows to integrate these different factors in a transparent and explicit way, allowing to account for components associated with the natural host, the intermediate host, and the environment. So, for a constant amount of resource in surveillance, this may increase the chance of NiV detection in comparison to the current scheme.

\section{Methods}

\section{Data collection}

The analysis of suitability of NiV transmission in pigs in Thailand was analyzed at the level of 100 - $m$ pixel on one hand (spatial model), and of the farm on the other hand (farm model). The spatial model was based on spatial risk factors that could influence the distribution of $\mathrm{NiV}$ and therefore determine the suitability of NiV transmission in pigs. The study area for the spatial model included 27 provinces of western, central and eastern Thailand, covering a total area of $93,826 \mathrm{~km}^{2}$ (Fig. 5a). The area was selected following previous studies [19-21] reporting colonies of flying foxes belonging to two species: the Lyle's flying fox ( $P$. lylei) living in central Thailand, and the Large flying fox or Greater flying fox (P. vampyrus) living along the coast of eastern Thailand. Recently, there were 22 colonies reported in these areas [21].

The primary data used in this study are listed in Table 3. The bat preferred areas were modeled in a previous study using Ensemble modeling (EM) by Thanapongtharm et al (2015) [21]. Distance risk factors were processed in ArcGIS 10.2 with the cost distance tool, and the objects from which the nearest distances were estimated included the bat colonies, forests, orchards, and water bodies. The bat colonies' coordinates were provided by Department of National Park, Wildlife and Conservation [46] whereas the vector data of forests, orchards, and water bodies distribution were provided by Land Development Department (LDD) [47]. The human population density raster data set at $100-\mathrm{m}$ resolution was obtained from the Worldpop project [48]. For pigs, we used the pig population density modeled using a Random Forest (RF) by Thanapongtharm et al (2016) [18]. All geographical data were converted in raster data sets with a 100-m resolution to match the resolution of the finest data set. In this step, ArcGIS 10.2 software was used to manage all geoprocessing.

For the farm model, risk factors at the farm level such as biosecurity measures and characteristics of farms' environments were used to evaluate the suitability of $\mathrm{NiV}$ infection. We selected 89 pig farms (25\%) out of a total of 359 pig farms located in a $30-\mathrm{km}$ radius surrounding two 


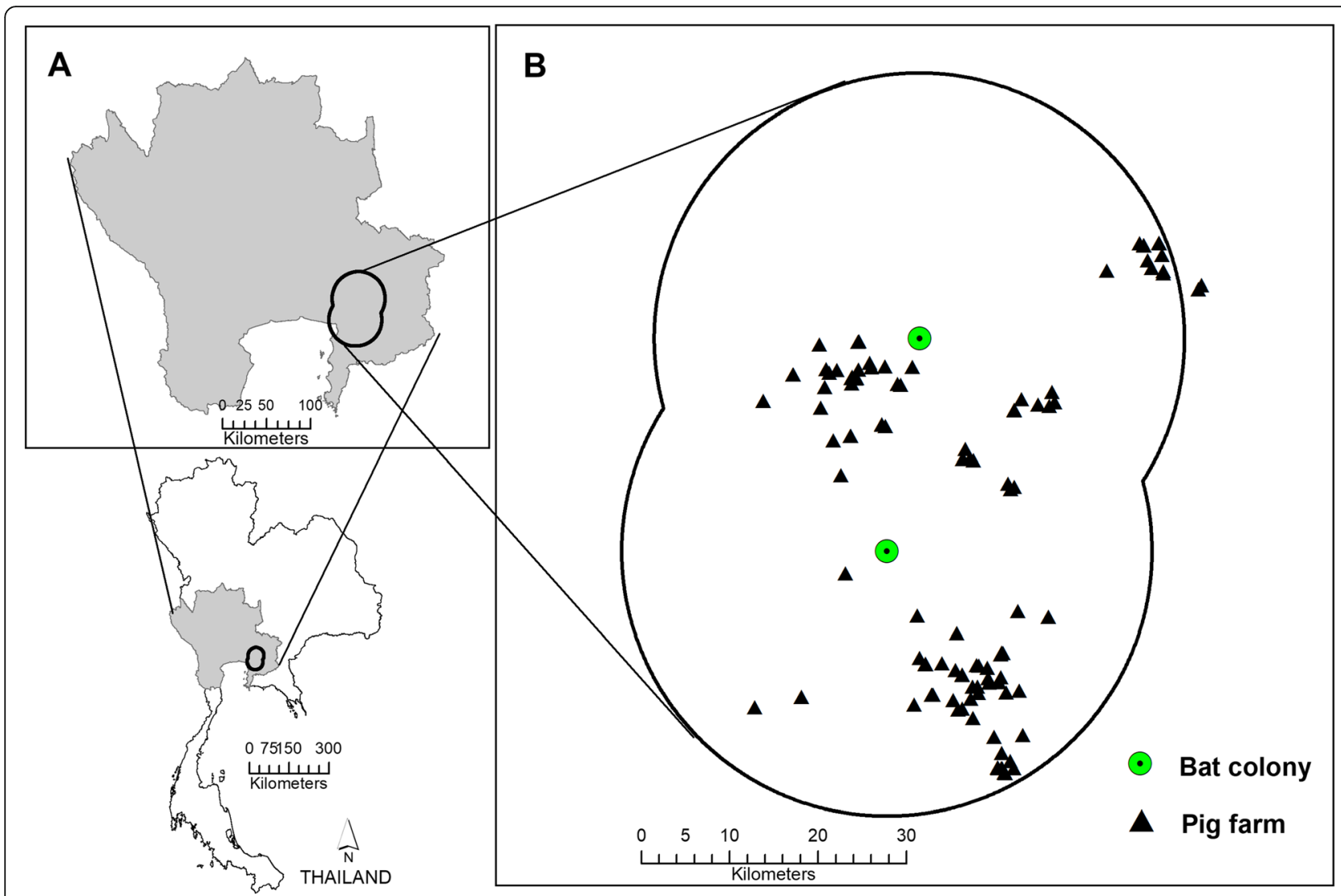

Fig. 5 Study area for suitability evaluation of NiV transmission in pigs. a Study areas of the spatial model covering $93,826.2 \mathrm{~km}^{2}$ of 27 provinces across western, central, and eastern Thailand and (b) of the farm model, including a 30-km radius surrounding two bat colonies: Wat Luangprommawat (lower gray dot) and Wat Phobangkla (upper gray dot)

bat colonies in the East of Thailand: Wat Luangprommawat in Chonburi province and Wat Phobangkla in Chacheongsao province (Fig. 5b). This radius was determined based on previous knowledge of bats foraging behaviors. Using high-resolution GPS loggers, Weber et al (2015) showed that maximum linear distances between day roosts and foraging areas for flying foxes at these two temples ranged between 2.2 and $23.6 \mathrm{~km}$ [36]. Pig farms within $30 \mathrm{~km}$ were selected with criteria as follows: i) farms with low biosecurity, ii) open house system, and iii) there were orchards close to the pig house or farm.

The defined factors used to carry out this study are listed in Table 2. We designed questionnaire on mobile application and used it to evaluate the suitability of pig farms to NiV transmission which were located in the study area. Farmers were provided all of the information required regarding their participation in the study to obtain their informed consent.

\section{Data analysis}

In the absence of $\mathrm{NiV}$ positive found in pigs through surveillance that would allow data-driven approach, an alternative to map the suitability of infection through the integration of several risk factors is to use knowledgedriven models such as Multi-criteria Decision Analysis (MCDA). MCDA is a static knowledge-driven model which aims to rank best choices by defining a set of weighted rules based on existing published and/or expert knowledge [23]. Many MCDA methods have been developed since 1960s [49] including the Multi-Attribute Utility Theory (MAUT), outranking (PROMETHEE and ELECTRE), and the Analytical Hierarchy Process (AHP), the later having significantly expanded in uses over the last decade [22].

AHP was used in the present study, for its power and simplicity $[22,50]$, and involved the implementation of the following sequence of analytical steps [23]: 1) the definition of risk factors; 2) the standardization of factors; 3 ) the definition of the relative importance of each factor; 4) the combination of all factors and constraints to produce a final weighted estimate of suitability; and 5) a sensitivity and uncertainty analysis (Fig. 6). The decision making part of the analytical procedure (step 1-3) was implemented in Microsoft excel, while their implementation in term of spatial 


\section{Suitability evaluation}

Spatial level

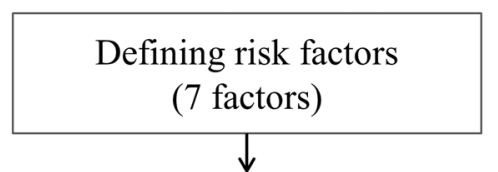

Standardizing the factors

(Fuzzy membership functions)

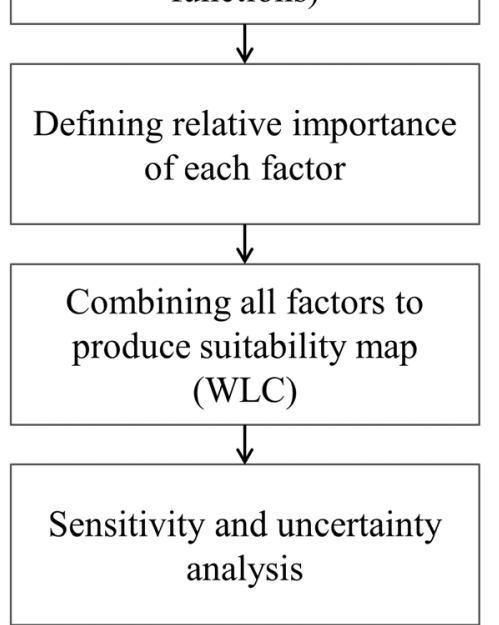

Farm level

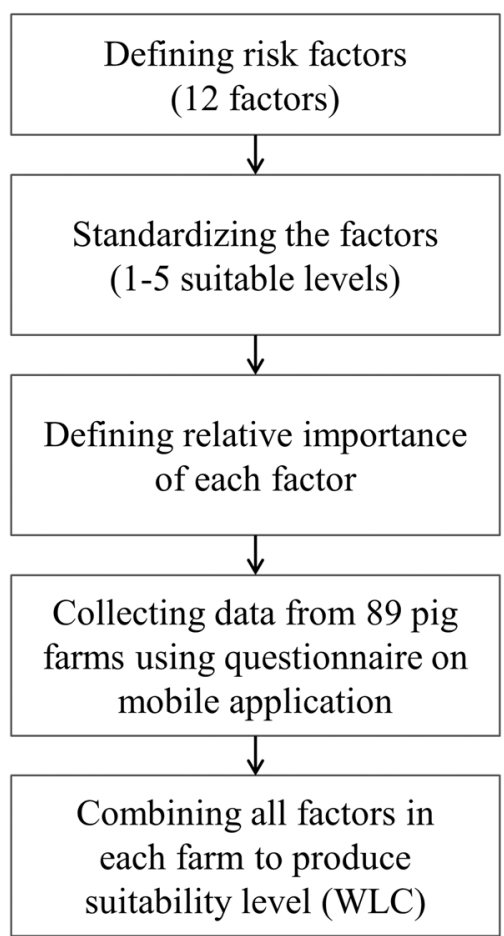

Fig. 6 Diagram of the suitability evaluation process followed for the spatial and the farm models

distribution was performed using $\mathrm{R}$ (Raster package [51]), IDRISI [52] and ArcGIS 10.2 [53].

\section{Definition and standardization of the risk factors}

A workshop was organized to go through the decision-making process, which was attended by 20 experts in epidemiology, virology, pig farming systems, and bats' ecology. The experts were divided into two groups, for the spatial and farm models, respectively.

Factors were standardized so that they could be compared. For the spatial model, the experts defined the relationship between the values of each factor and the suitability of $\mathrm{NiV}$ distribution as ranging from 0 (unsuitable) to 1 (highly suitable) by using fuzzy membership functions. Four types of relationships were proposed to the experts: linear, sigmoidal (s-shaped), $\mathrm{j}$-shaped, and user-defined, with increasing, decreasing, or symmetric functions [30]. The FUZZY tool from the IDRISI software was used to implement this standardization step. The FUZZY tool requires the position along the $\mathrm{X}$ axis of each risk factor of 4 parameters ( $a, b, c$, and d) governing the shape of the fuzzy membership function [54]. For the risk factors of the farm model, the experts defined the relationship between each of the factors and suitability using a 6 points scale: 0: constraint (i.e. not suitable at all), 1: very low, 2: low, 3: medium, 4: high, and 5: very high).

\section{Definition the relative importance of each factor}

To define the relative importance of each factor, a pairwise comparison technique was used. The procedure consisted in comparing each pairs of factors by a nine-point continuous comparison scale (Table 4). Experts first assigned their scores for all pairwise comparisons individually, and then assigned the final scores altogether. The weight value for each factor (Wi) was calculated by taking the eigenvector corresponding to the largest eigenvalue of the pairwise score matrix, and then normalizing the sum of the components to a unity [55-57]. The consistency of the matrix was verified using consistency ratio (CR), 
Table 4 Nine-point scale values used in the pairwise comparison of factors

\begin{tabular}{ll}
\hline Intensity of importance & Description \\
\hline 1 & Equal importance \\
3 & Moderate importance \\
5 & Strong or essential importance \\
7 & Very strong or demonstrated importance \\
9 & Extreme importance \\
$2,4,6,8$ & Intermediate values \\
Reciprocals & Values for inverse comparison
\end{tabular}

which was calculated as the consistency index (CI) divided by random index (RI). CI is calculated as:

$$
C I=\frac{\lambda_{\max }-n}{n-1}
$$

where $\lambda_{\max }$ is the maximum eigenvalue of the judgement matrix and $\mathrm{n}$ is the number of factors. RI is derived from Saaty (1980) [58] and is entirely dependent on the number of factors in the analysis (Table 5). If CR is higher than 0.10 , then some pairwise values need to be reconsidered and the process is repeated until the desired value of CR less than 0.10 is reached [59].

\section{Combination of all factors to produce a final weighted estimate of suitability}

Weighted Linear Combination (WLC) [60] method was used to combine all factors and constraints to generate the suitability maps (spatial model) and risk level of each pig farm (farm model). This method produces a final weighted estimate of suitability for each location in the study area. In the WLC, each standardized factor is multiplied by its corresponding weight, these are summed, and then the sum is divided by the number of factors. Its equation is as:

$$
S=\sum_{i=1}^{n} w_{i} x_{i} c_{j}
$$

where $w_{i}$ is the weight of criteria $\mathrm{i}, x_{i}$ is the criterion score of criteria $i$ (value of corresponding the raster cell in the criterion raster map), $n$ is the number of criteria, $c_{j}$ is the criterion score ( 1 or 0 ) of constraint $j$.

For the spatial model, WLC was implemented using IDRISI software (Multi-criteria evaluation tool) to produce a final weighted estimate of suitability for each pixel in the study area. For the farm model, we combined all factors and constraints using WLC to produce a final weighted estimate of suitability of each pig farm.

\section{Sensitivity and uncertainty analyses}

Sensitivity Analysis (SA) was implemented by applying One-At-a-Time (OAT) method, which works by changing one input factors at a time and evaluating the effect of the change on the output [61]. Even though there are three most commonly used ways to measure the sensitivity, by changing the values of the criteria, by changing the relative importance of criteria, and by changing the weights of the criteria, we only investigated the later. We choose the OAT method for its simplicity and good comparability results.

The SA was performed for each objective using a previously proposed framework [56], whereby two parameters are set: a step size of $1 \%$ and a range of $50 \%( \pm$ $25 \%)$. By changing one factor at a time, all other factor can be fixed, at least to a great extent, to their central or baseline value. The sum of all criteria weights at any percent change (PC) level should always be equal to 1 . The weight of the main changing criterion $\left(W\left(c_{m}, p c\right)\right)$ at a certain PC level can be calculated as

$$
W\left(c_{m}, p c\right)=W\left(c_{m}, 0\right)+\left(W\left(c_{m}, 0\right) * p c\right), \quad 1 \leq m \leq n
$$

where $W\left(c_{m}, 0\right)$ is the weight of the main changing criterion $c_{m}$ at the base run (the original weights). The weights of the other criteria $W\left(c_{i}, p c\right)$ are adjusted proportionally in accordance with $W\left(c_{m}, p c\right)$ in order to maintain the sum of all criteria weights at any PC of 1 , with the equation is

$$
W\left(c_{i}, p c\right)=\left(1-W\left(c_{m}, p c\right)\right) *\left(\frac{W\left(c_{i}, 0\right)}{1-W\left(c_{m}, 0\right)}\right), \quad i \neq m, 1 \leq i \leq n
$$

where $W\left(c_{i}, 0\right)$ is weight of the $i$-th criterion $c_{i}$ at the base run.

We evaluated this step using the mean of the absolute change rate (MACR) [62]. In each simulation, the original suitability map (the original weights) and the out-

\begin{tabular}{|c|c|c|c|c|c|c|c|c|c|c|c|c|c|c|c|}
\hline No of factors & 1 & 2 & 3 & 4 & 5 & 6 & 7 & 8 & 9 & 10 & 11 & 12 & 13 & 14 & 15 \\
\hline $\mathrm{Rl}$ & 0.00 & 0.00 & 0.58 & 0.90 & 1.12 & 1.24 & 1.32 & 1.41 & 1.46 & 1.49 & 1.51 & 1.54 & 1.56 & 1.57 & 1.58 \\
\hline
\end{tabular}
put map of the alternative model (changing criterion weights) were quantitatively matched through a

Table 5 Saaty's random index (RI) 
pixel-by-pixel comparison. The MACR was calculated by the following equation:

$$
\operatorname{MARC}\left(w_{J}, c r\right)=\sum_{k=1}^{N} \frac{1}{N} \times\left|\frac{R_{k}\left(w_{j}, c r\right)-R_{0}}{R_{0}}\right| \times 100 \%
$$

where $\operatorname{MARC}\left(w_{J}, c r\right)$ is the mean absolute value of the change rate with $\bar{w}_{J}$ as a change rate, and $\mathrm{N}$ is the number of pixels. In addition, an uncertainty surface resulting from the changes in weights was produced for the study area, representing the standard deviation of the different suitability maps $[30,63]$.

\section{Abbreviations \\ AHP: Analytical Hierarchy Process; DLD: Department of Livestock Development; EM: Ensemble modeling; FMD: Foot and mouth disease; HeV: Hendra virus; HPAl: Highly pathogenic avian influenza; LDD: Land Development Department; MACR: Mean of the absolute change rate; MAUT: Multi-Attribute Utility Theory; MCDA: Multi-criteria decision analysis; NiV: Nipah virus; OAT: One-At-a-Time; PC: Percent change; PRRS: Porcine Reproductive and Respiratory Syndrome; PSA: Potential surface analysis; RF: Random forest; SA: Sensitivity Analysis; STD: Standard deviation; WLC: Weighted Linear Combination}

\section{Acknowledgements}

We cordially thank the staff of pig project under Bureau of Disease Control and Veterinary Services, National Institute of Animal Health (NIAH), Chacheongsao provincial livestock office, Chonburi provincial livestock office, and BIOPHICS for cooperation and helpfulness. We also thank USAID and FAO for financial and technical supports.

\section{Funding}

Part of this work was supported through the USAID/FAO grant (LOA/RAP/ 2016/32).

\section{Availability of data and materials}

The data that support the findings of this study are available from the Department of Livestock Development but restrictions apply to the availability of these data, which were used under license for the current study, and so are not publicly available. Data are however available from the authors upon reasonable request and with permission of the Department of Livestock Development.

\section{Authors' contributions}

WT and MG conceived and designed the study. WT generated the raw data and performed statistical analysis with contributions from MG and MP. WT drafted the paper, which MG and MP critically reviewed. WK, KW, SD, AW, WW, and DS provided data. All authors read and approved the final manuscript.

\section{Authors' information}

Not application

\section{Ethics approval and consent to participate}

This study was approved by the Research Committee of the Bureau of Disease Control and Veterinary Services, Department of Livestock Development, Thailand (Permit number: 0610.04/449).

\section{Consent for publication}

Not applicable

\section{Competing interests}

The authors declare that they have no competing interests.

\section{Publisher's Note}

Springer Nature remains neutral with regard to jurisdictional claims in published maps and institutional affiliations.

\section{Author details}

'Department of Livestock Development (DLD), Bangkok, Thailand. ${ }^{2}$ UMR 1225 IHAP, Université de Toulouse, INRA, ENVT, Toulouse, France. ${ }^{3}$ Department of Clinical Sciences and Public Health, Faculty of Veterinary Science, Mahidol University, Nakhon Pathom, Thailand. ${ }^{4}$ Food and Agriculture Organization of the United Nations, Regional Office for Asia and the Pacific, Bangkok, Thailand. ${ }^{5}$ USAID Regional Development Mission Asia, Bangkok, Thailand. '5patial epidemiology Lab. (SpELL), University of Brussels, Brussels, Belgium. ${ }^{7}$ Fonds National de la Recherche Scientifique (FNRS), University of Brussels, Brussels, Belgium.

Received: 7 June 2018 Accepted: 21 February 2019

Published online: 04 March 2019

\section{References}

1. Murray K, Selleck P, Hooper P, Hyatt A, Gould A, Gleeson L, et al. A morbillivirus that caused fatal disease in horses and humans. Science. 1995; 268:94-7.

2. WHO Collaborating Centre for Viral Zoonoses,. Nipah virus infection. 2008.

3. Chua KB, Lek Koh C, Hooi PS, Wee KF, Khong JH, Chua BH, et al. Isolation of Nipah virus from Malaysian island flying-foxes. Microbes Infect. 2002;4:145-51.

4. Johara MY, Field H, Rashdi AM, Morrisy C, van der Heide B, Rota P, et al. Nipah virus infection in bats (order Chiroptera) in peninsular Malaysia. Emergin Infect Dis. 2001;7:439-41.

5. Mohd Nor MN, Gan CH, Ong BL. Nipah virus infection of pigs in peninsular Malaysia. Rev Sci Tech Int Off Epizoot. 2000;19:160-5.

6. DEPI - Flying-foxes. http://www.depi.vic.gov.au/environment-and-wildlife/ wildlife/flying-foxes. Accessed 15 May 2014.

7. Reynes J-M, Counor D, Ong S, Faure C, Seng V, Molia S, et al. Nipah virus in Lyle's flying foxes, Cambodia. Emerg Infect Dis. 2005;11:1042-7.

8. Wacharapluesadee S, Lumlertdacha B, Boongird K, Wanghongsa S, Chanhome L, Rollin P, et al. Bat Nipah virus, Thailand. Emerg Infect Dis. 2005;11:1949-51.

9. Luby S, Rahman M, Hossain M, Blum L, Husain M, Gurley E, et al. Foodborne transmission of Nipah virus, Bangladesh. Emerg Infect Dis. 2006;12:1888-94.

10. Chadha MS, Comer JA, Lowe L, Rota PA, Rollin PE, Bellini WJ, et al. Nipah virusassociated encephalitis outbreak, Siliguri, India. Emerg Infect Dis. 2006;12:235-40.

11. Tan K-S, Tan C-T, Goh K-J. Epidemiological aspects of Nipah virus infection. Neurol J Southeast Asia. 1999;4:77-81.

12. Chua K, Chua B, Wang C. Anthropogenic deforestation, El Niño and the emergence of Nipah virus in Malaysia. Malays J Pathol. 2001;24(1):15-21.

13. Luby SP, Gurley ES, Hossain MJ. Transmission of human infection with Nipah virus. Clin Infect Dis. 2009:49:1743-8.

14. Wacharapluesadee S, Boongird K, Wanghongsa S, Ratanasetyuth N, Supavonwong P, Saengsen D, et al. A longitudinal study of the prevalence of Nipah virus in Pteropus lylei bats in Thailand: evidence for seasonal preference in disease transmission. Vector-Borne Zoonotic Dis. 2010;10:183-90.

15. Pathchimasiri T, Kalpravidh W, Damrongwatanapokin S, Chantamaneechote T, Daniels P, Buranathai C. Immunohistochemistry investigation of Nipah Virus : a retrospective study in Thailand. 11th Int Symp world Assoc vet lab Diagn OIE Semin. Biotechnol. 2003:44-5.

16. Department of Livestock Development. 2012. Animal Health in Thaialnd 2011. Bangkok, Thailand.

17. OIE World Animal Health Information System. http://www.oie.int/wahis 2/ public/wahid.php/Countryinformation/Animalsituation. Accessed 15 May 2014.

18. Thanapongtharm W, Linard C, Chinson P, Kasemsuwan S, Visser M, Gaughan $A E$, et al. Spatial analysis and characteristics of pig farming in Thailand. BMC Vet Res. 2016;12. https://doi.org/10.1186/s12917-016-0849-7.

19. Boonkird K, Wanghongsa S. On the population number and distribution fo flying foxes (Pteropus lylei) in central plain. Wildl Yearb. 2004;5:89-100.

20. Sedwisai P, Changbunjong T, Chamsai T, Yongyuttawichai P, Sangkachai N, Weluwanarak $\mathrm{T}$, et al. The distribution of flying fox (Pteropus spp.) in the central region of Thailand. J Appl Anim Sci. 2011;4(3):21-9.

21. Thanapongtharm W, Linard C, Wiriyarat W, Chinsorn P, Kanchanasaka B, Xiao $X$, et al. Spatial characterization of colonies of the flying fox bat, a carrier of Nipah virus in Thailand. BMC Vet Res. 2015;11. https://doi.org/10.1186/ s12917-015-0390-0.

22. Huang IB, Keisler J, Linkov I. Multi-criteria decision analysis in environmental sciences: ten years of applications and trends. Sci Total Environ. 2011;409: 3578-94. 
23. Pfeiffer DU, Robinson T, Stevenson M, Stevens KB, Rogers DJ, Clements ACA. Spatial analysis in epidemiology. New York: Oxford university; 2008.

24. Gilbert M, Chaitaweesub P, Parakamawongsa T, Premashthira S, Tiensin T, Kalpravidh W, et al. Free-grazing ducks and highly pathogenic avian influenza, Thailand. Emerg Infect Dis. 2006;12:227-34.

25. Van Boeckel TP, Thanapongtharm W, Robinson T, Biradar CM, Xiao X, Gilbert M. Improving risk models for avian influenza: the role of intensive poultry farming and flooded land during the 2004 Thailand epidemic. PLoS One. 2012;7:e49528

26. Gilbert M, Xiao X, Pfeiffer DU, Epprecht M, Boles S, Czarnecki C, et al. Mapping H5N1 highly pathogenic avian influenza risk in Southeast Asia. Proc Natl Acad Sci. 2008;105:4769-74.

27. Thanapongtharm W, Van Boeckel TP, Biradar C, Xiao X, Gilbert M. Rivers and flooded areas identified by medium-resolution remote sensing improve risk prediction of the highly pathogenic avian influenza $\mathrm{H} 5 \mathrm{~N} 1$ in Thailand. Geospat Health. 2013;8:193

28. Thanapongtharm W, Linard C, Pamaranon N, Kawkalong S, Noimoh T, Chanachai $\mathrm{K}$, et al. Spatial epidemiology of porcine reproductive and respiratory syndrome in Thailand. BMC Vet Res. 2014;10. https://doi.org/10. 1186/s12917-014-0174-y.

29. Tran A, Trevennec C, Lutwama J, Sserugga J, Gély M, Pittiglio C, et al. Development and assessment of a geographic knowledge-based model for mapping suitable areas for Rift Valley fever transmission in eastern Africa. PLoS Negl Trop Dis. 2016;10:e0004999.

30. Paul MC, Goutard FL, Roulleau F, Holl D, Thanapongtharm W, Roger FL, et al. Quantitative assessment of a spatial multicriteria model for highly pathogenic avian influenza H5N1 in Thailand, and application in Cambodia. Sci Rep. 2016:6:31096.

31. Stevens KB, Pfeiffer DU. Spatial modelling of disease using data- and knowledge-driven approaches. Spat Spatio-Temporal Epidemiol. 2011;2:125-33.

32. Rahman SA, Hassan SS, Olival KJ, Mohamed M, Chang L-Y, Hassan L, et al. Characterization of Nipah virus from naturally infected Pteropus vampyrus bats, Malaysia. Emerg Infect Dis. 2010;16:1990-3.

33. Yadav PD, Raut CG, Shete AM, Mishra AC, Towner JS, Nichol ST, et al. Detection of Nipah virus RNA in fruit bat (Pteropus giganteus) from India. Am J Trop Med Hyg. 2012;87:576-8.

34. RTSD. Royal Thai Survey Deparment. 2015. http://www.rtsd.mi.th/. Accessed 18 Sept 2015.

35. Van Boeckel TP, Thanapongtharm W, Robinson T, D'Aietti L, Gilbert M. Predicting the distribution of intensive poultry farming in Thailand. Agric Ecosyst Environ. 2012;149:144-53.

36. Weber N, Duengkae P, Fahr J, Dechmann DKN, Phengsakul P, Khumbucha W, et al. High-resolution GPS tracking of Lyle's flying fox between temples and orchards in Central Thailand: GPS tracking of flying foxes. J Wildl Manag. 2015;79:957-68.

37. Rainho A, Palmeirim JM. The importance of distance to resources in the spatial modelling of bat foraging habitat. PLoS One. 2011;6:e19227.

38. Adams RA, Hayes MA. Water availability and successful lactation by bats as related to climate change in arid regions of western North America. J Anim Ecol. 2008;77:1115-21.

39. Welbergen JA, Klose SM, Markus N, Eby P. Climate change and the effects of temperature extremes on Australian flying-foxes. Proc R Soc B Biol Sci. 2008;275:419-25.

40. Killer climate: tens of thousands of flying foxes dead in a day. http://www. brisbanetimes.com.au/queensland/killer-climate-tens-of-thousands-of-flyingfoxes-dead-in-a-day-20140225-33drr.html. Accessed 16 May 2014.

41. Chua KB. Nipah virus outbreak in Malaysia. J Clin Virol. 2003;26:265-75.

42. Jamal SM, Belsham GJ. Foot-and-mouth disease: past, present and future. Vet Res. 2013;44:116.

43. FAO. Improving bio-security practices to control highly pathogenic avian influenza. 2011.

44. FAO, OIE \& world bank. Good practices for biosecurity in the pig sector. 2010.

45. Stärk KD, Regula G, Hernandez J, Knopf L, Fuchs K, Morris RS, et al. Concepts for risk-based surveillance in the field of veterinary medicine and veterinary public health: review of current approaches. BMC Health Serv Res. 2006;6. https://doi.org/10.1186/1472-6963-6-20.

46. National Park, Wildlife and Plant Conservation. http://portal.dnp.go.th/. Accessed 15 Apr 2017.

47. Land Development Department. http://www.ldd.go.th/www/lek_web/. Accessed 15 Apr 2017.
48. Gaughan AE, Stevens FR, Linard C, Jia P, Tatem AJ. High resolution population distribution maps for Southeast Asia in 2010 and 2015. PLoS One. 2013;8:e55882.

49. Voogd $\mathrm{H}$. Multicriteria evaluation for urban and regional planning. London: Pion, Ltd.; 1983.

50. Meng Y. A GIS-based multicriteria decision analysis approach for mapping accessibility patterns of housing development sites: a case study in Canmore, Alberta. J Geogr Inf Syst. 2011;03:50-61.

51. Hijmans RJ, van Etten J, Cheng J, Mattiuzzi M, Sumner M, Greenberg JA, et al. Raster: geographic data analysis and modeling. 2016. https://cran.rproject.org/web/packages/raster/index.html. Accessed 17 Apr 2017.

52. TerrSet Geospatial Monitoring and Modeling Software. https://clarklabs.org/ terrset/. Accessed 17 Apr 2017.

53. Esri: GIS Mapping Software, Spatial Data Analytics \& Location Platform. http://www.esri.com/. Accessed 17 Apr 2017.

54. Eastman JR. IDRISI Kilimanjaro guide to GIS and image processing. 2003. https://www.mtholyoke.edu/courses/tmillett/course/geog307/files/ Kilimanjaro\%20Manual.pdf. Accessed 18 Apr 2017.

55. Ishizaka A, Labib A. Review of the main developments in the analytic hierarchy process. Expert Syst Appl. 2011;38:14336-45.

56. Chen $Y, Y u$ J, Khan S. Spatial sensitivity analysis of multi-criteria weights in GIS-based land suitability evaluation. Environ Model Softw. 2010;25:1582-91.

57. Rosenbloom ES. A probabilistic interpretation of the final rankings in AHP. Eur J Oper Res. 1997;96:371-8.

58. Donegan HA, Dodd FJ. A note on saaty's random indexes. Math Comput Model. 1991:15:135-7.

59. Saaty TL. The analytic hierarchy process. New York: McGraw-Hill; 1980.

60. Malczewski J. GIS-based land-use suitability analysis: a critical overview. Prog Plan. 2004;62:3-65.

61. Daniel C. One-at-aTime plans. J Am Stat Assoc. 1973;68:353-60.

62. Xu E, Zhang H. Spatially-explicit sensitivity analysis for land suitability evaluation. Appl Geogr. 2013;45:1-9.

63. Ligmann-Zielinska A, Jankowski P. Spatially-explicit integrated uncertainty and sensitivity analysis of criteria weights in multicriteria land suitability evaluation. Environ Model Softw. 2014:57:235-47.

Ready to submit your research? Choose BMC and benefit from:

- fast, convenient online submission

- thorough peer review by experienced researchers in your field

- rapid publication on acceptance

- support for research data, including large and complex data types

- gold Open Access which fosters wider collaboration and increased citations

- maximum visibility for your research: over $100 \mathrm{M}$ website views per year

At BMC, research is always in progress.

Learn more biomedcentral.com/submissions 